\title{
Women's Struggles and Resilience through Photography
}

\section{Sumy Sadurni}

Sadurni, Sumy. 2020. 'Women's Struggles and Resilience through Photography.' Gender a výzkum / Gender and Research 21 (1): 116-129, http://dx.doi.org/10.13060/gav.2020.006.

\section{Youth in Uganda lead the fight for climate change}

Young Ugandan activists have been leading the global struggle against climate change, joining the Friday for Future movement - to represent their country and the African continent. Friday for Future, which was originally started in Sweden by famous climate activist Greta Thunberg, has not been as popular across the region. However, it has really set down roots in Uganda because of the strong youth leaders who have continued to raise awareness about climate change.

Leah Namugerwah (photo 1) is a 15-year-old activist who has been striking every Friday, skipping school in order to raise awareness of the current climate crisis we are living in. Part of her activism includes planting trees for special occasions, such as her birthday, and promoting more planting across Uganda. She has spoken in New York at climate forums and in other countries. She was inspired by Greta Thunberg and is often in touch with her to communicate on how to raise more awareness on these issues. Leah has also led protests and marches against climate change with youth from different parts of Kampala.

Vanessa Nakate's public profile (photo 3) grew last year when, during the Davos conference in 2019, she was cropped out of a photo by the Associated Press of her and four other activists including Greta Thunberg. 'You didn't erase a person, you erased a continent', she said after realising what had happened. Since then, she has become a prominent voice representing climate activism on the African continent. 


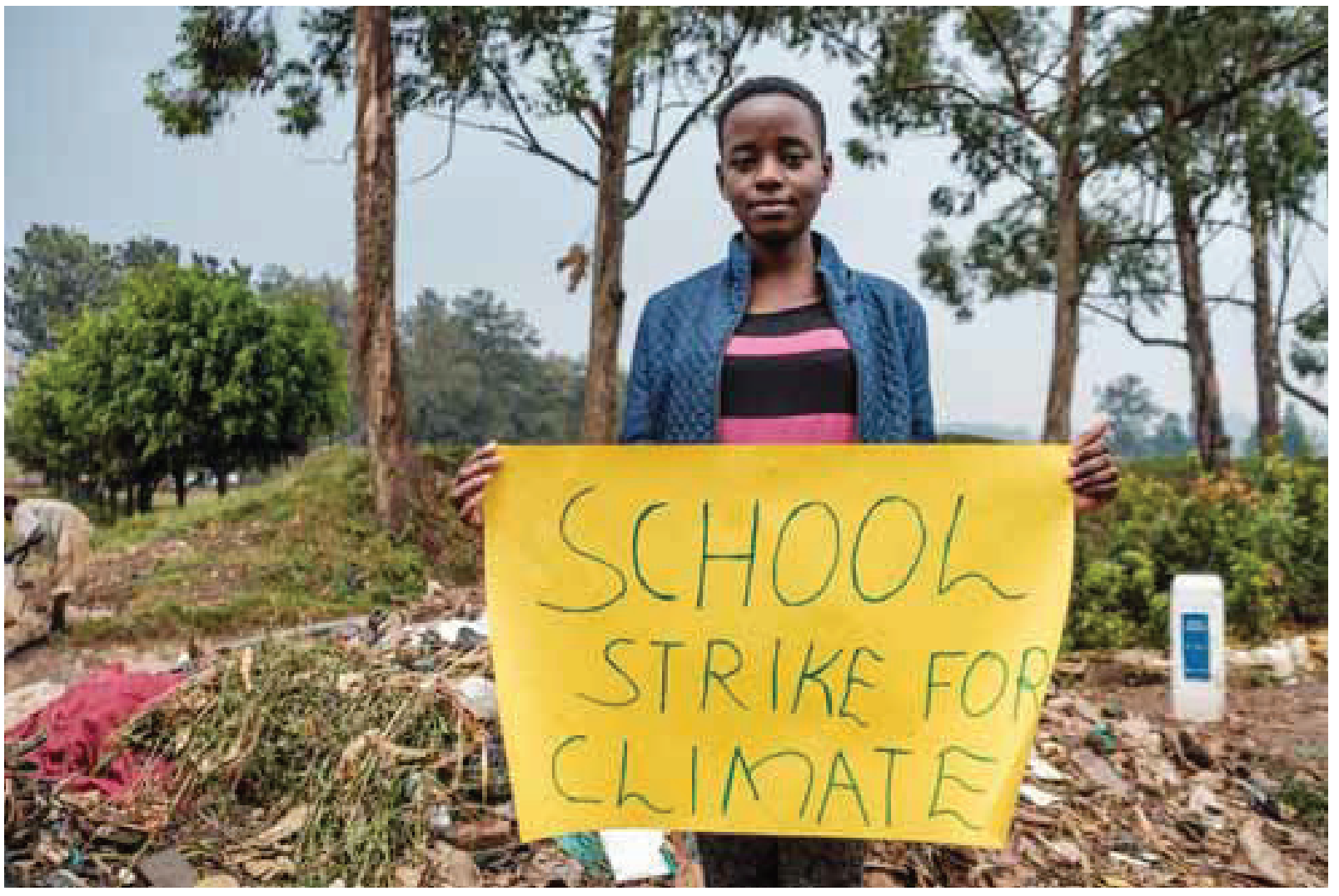

Leah Namugerwah is a climate change activist in Kampala, Uganda.

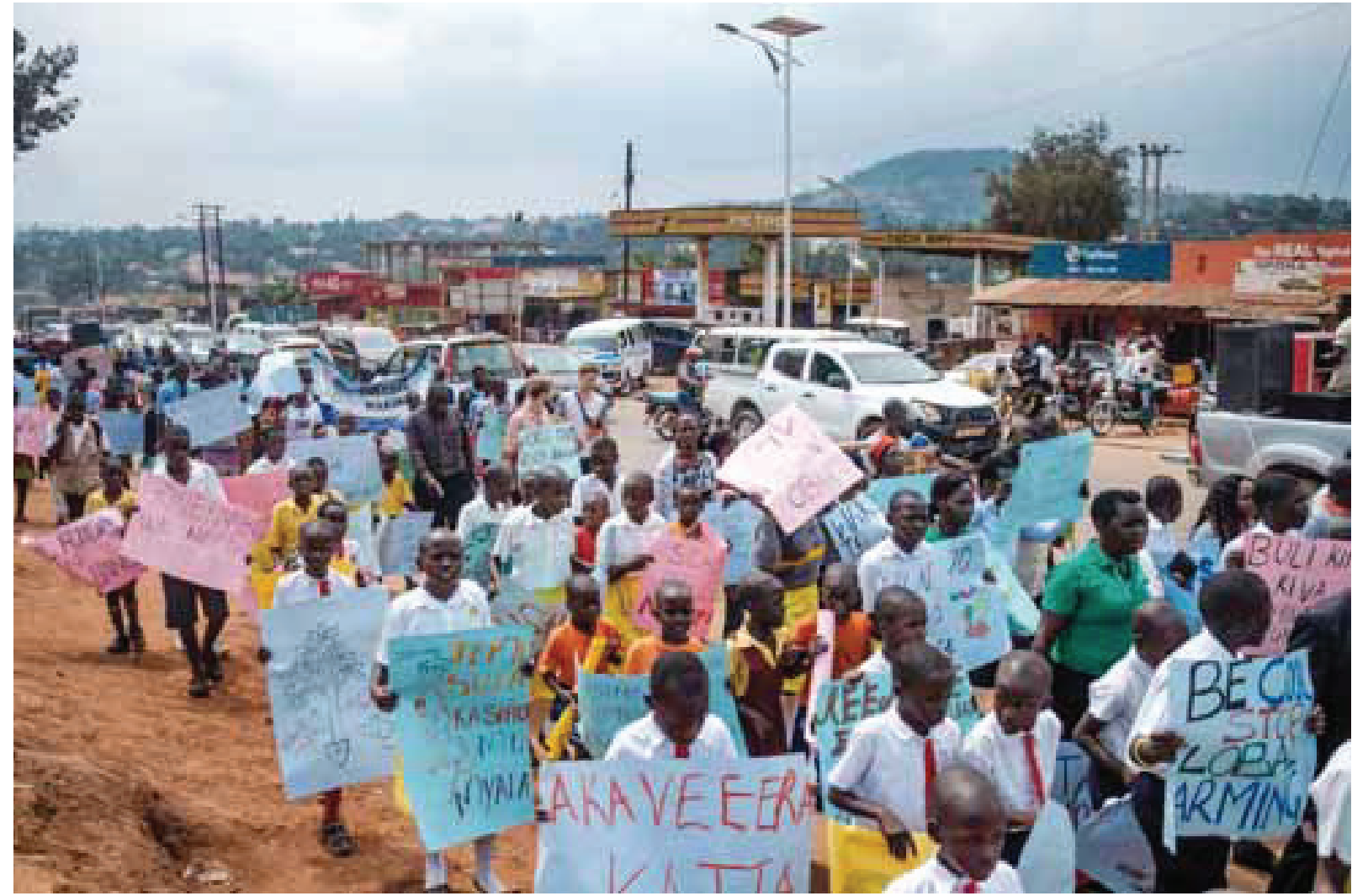

Youth march for climate change in Wakiso District on 21 September 2019. 


\section{DOKUMENT / THE GENDER FILE}

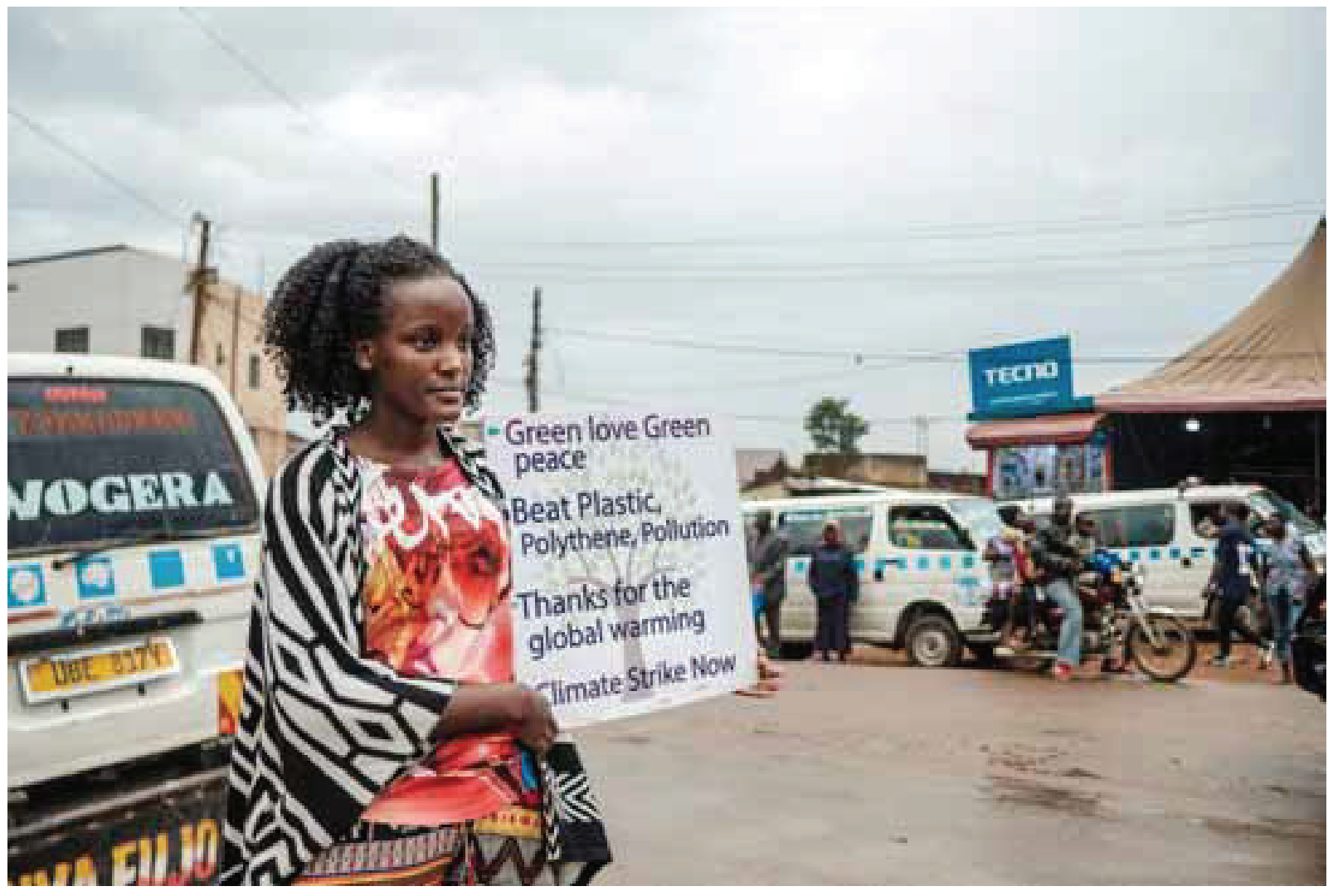

Vanessa Nakate is a prominent climate change activist in Uganda.

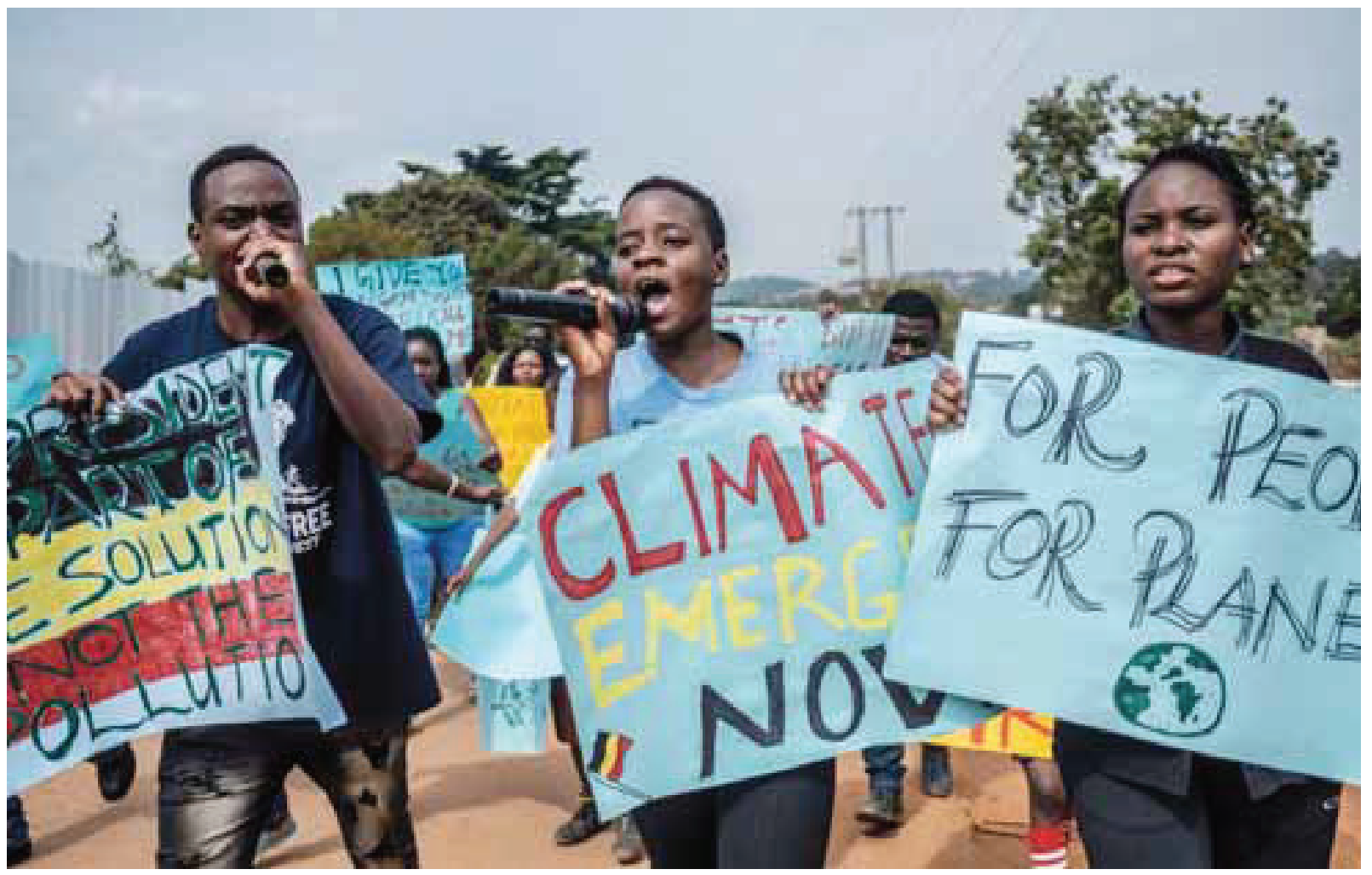

Youth, led by Leah Namugerwa, march for climate change in Wakiso District on 21 September 2019. 


\section{Women against the ritual cutting of female genitalia}

In the hills of Kapchorwa, close to the tourist destination of Sipi Falls in Eastern Uganda, a group of women is fighting against the ritual cutting of female genitalia. There are four types of female genital cutting, some more invasive than others. In this region, the most severe form of infibulation (type 3) has been practised. While the practice was outlawed in Uganda in 2010, like in other countries in the region, small pockets of society, mostly in the east of the country, still continue to perform this ritual. Most recently the practice was outlawed in Sudan in April 2020.

This collective of women known as 'The Tumboboi Grandmother's Group' gets together often and travels from village to village to educate men, women, and children about the medical dangers of infibulation. Most of these women were cut themselves when they were younger and understand the pain and the perils that come with this ritual. They target men specifically, as fathers are usually the ones who send their daughters to be cut in secret so that they can get a bigger dowry when they're married off.

They also talk to former cutters, women who used to be able to financially sustain themselves by performing ritual cutting but since the banning of the practice have been economically impacted. They are kind women who back then were just doing their jobs. They help reintegrate the cutters into society and ask them to join their group in order to spread the word even further in the region.

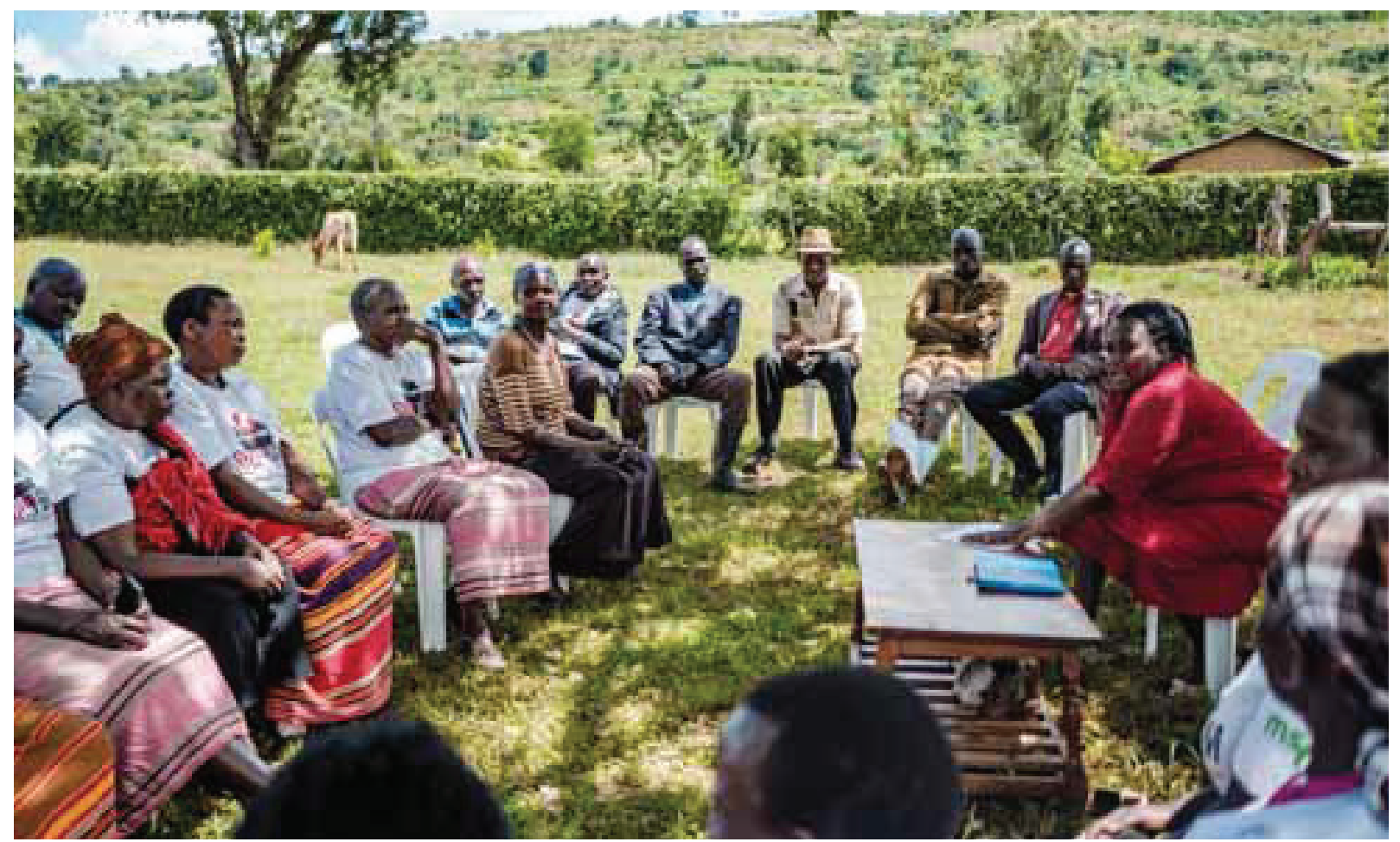

Women and men in Kapchorwa district, Eastern Uganda, meet to discuss how to eliminate the ritual cutting of women's genitalia. 


\section{DOKUMENT / THE GENDER FILE}

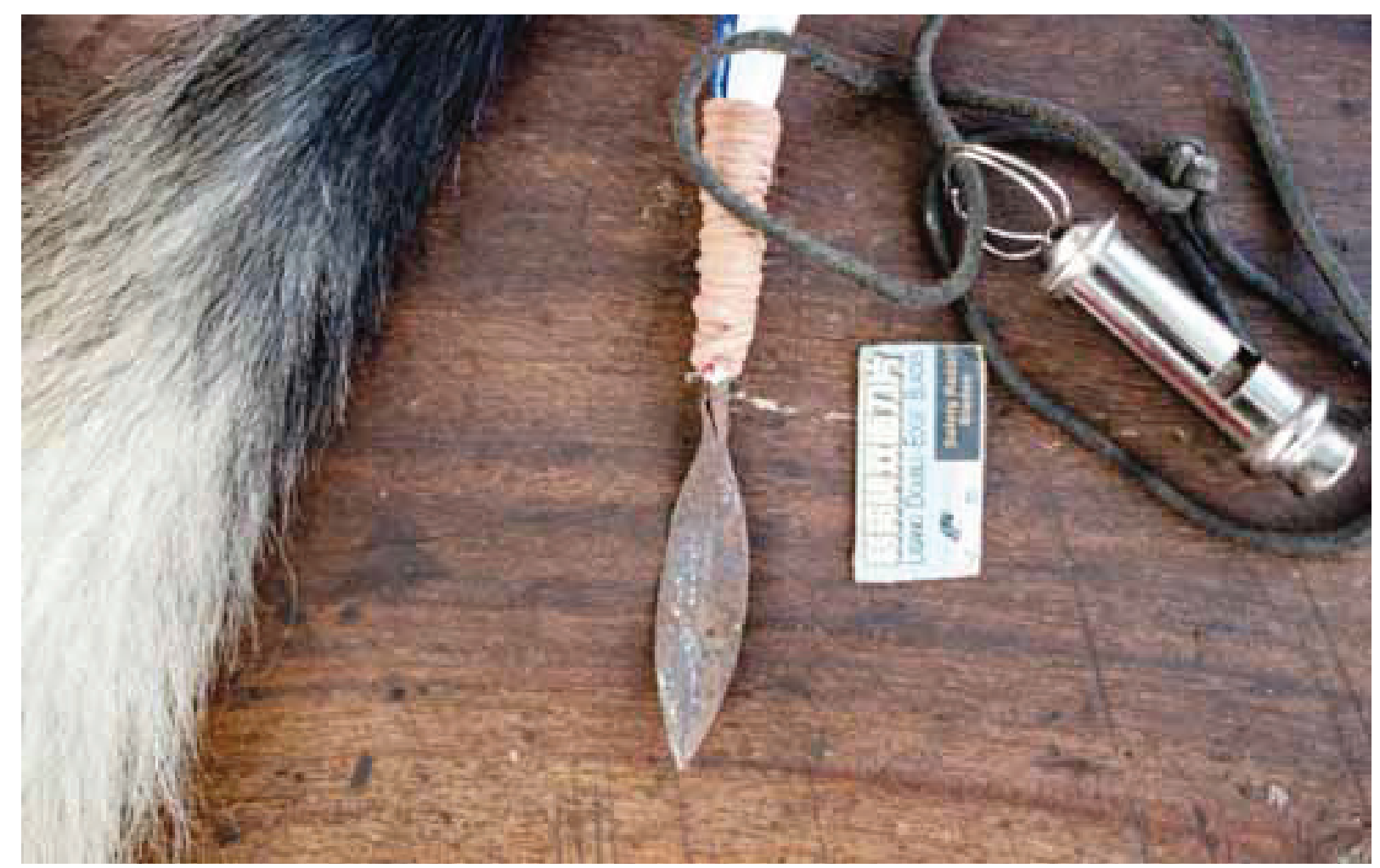

Tools used for the ritual cutting of women's genitalia.

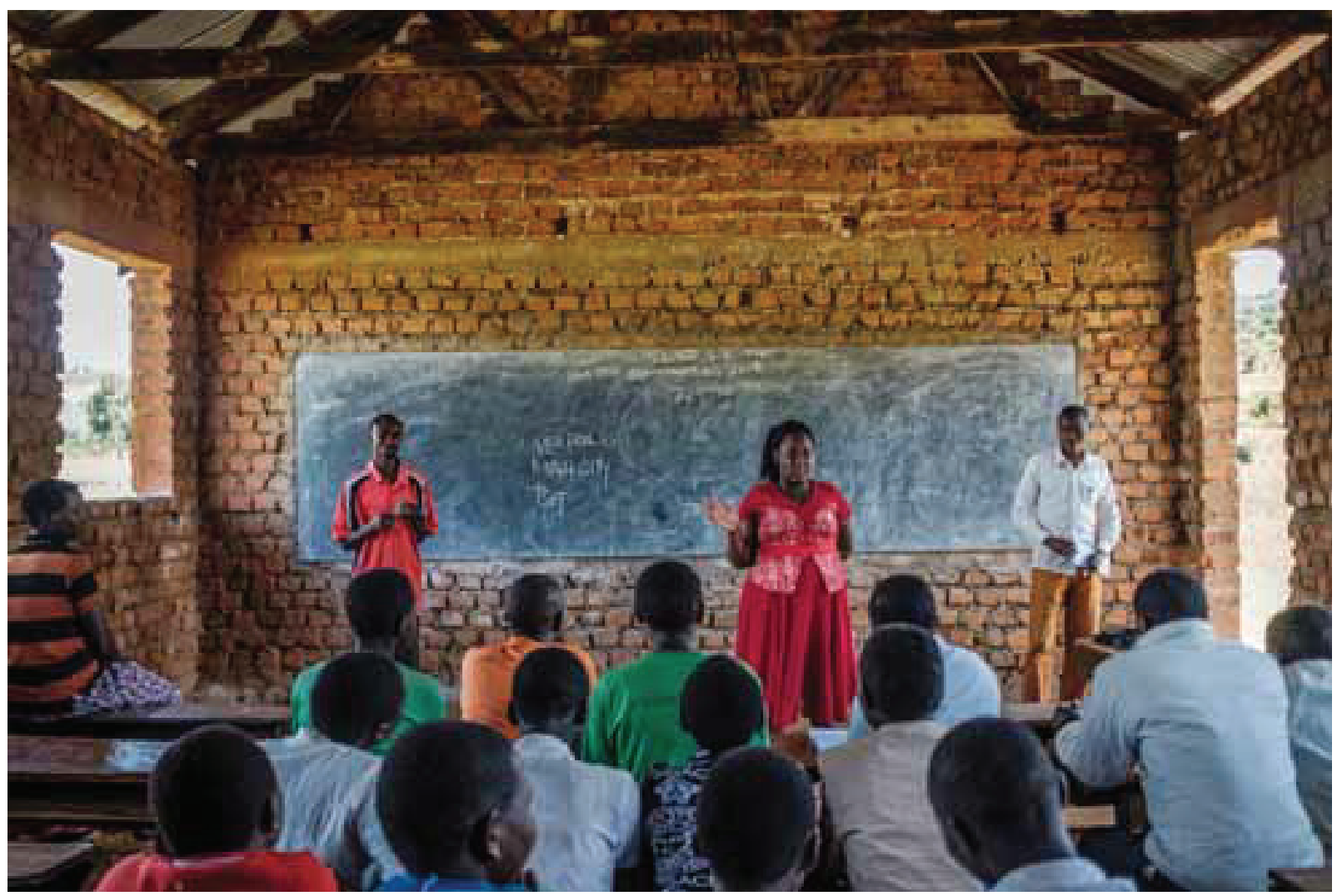

A school in Kapchorwa district, Eastern Uganda, educating children on the dangers of infibulation. 


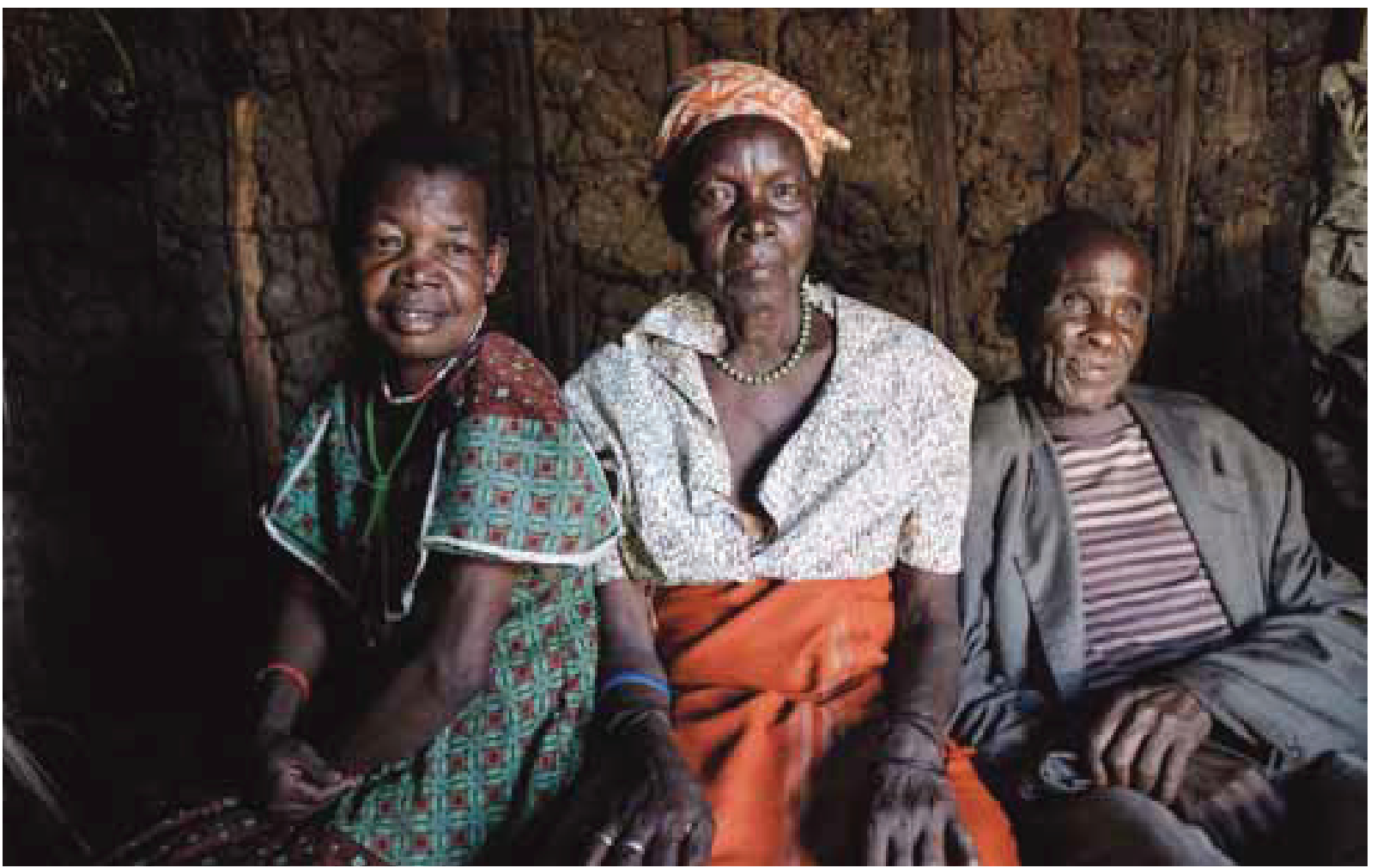

Local residents of Tomboboi town, in Eastern Uganda.

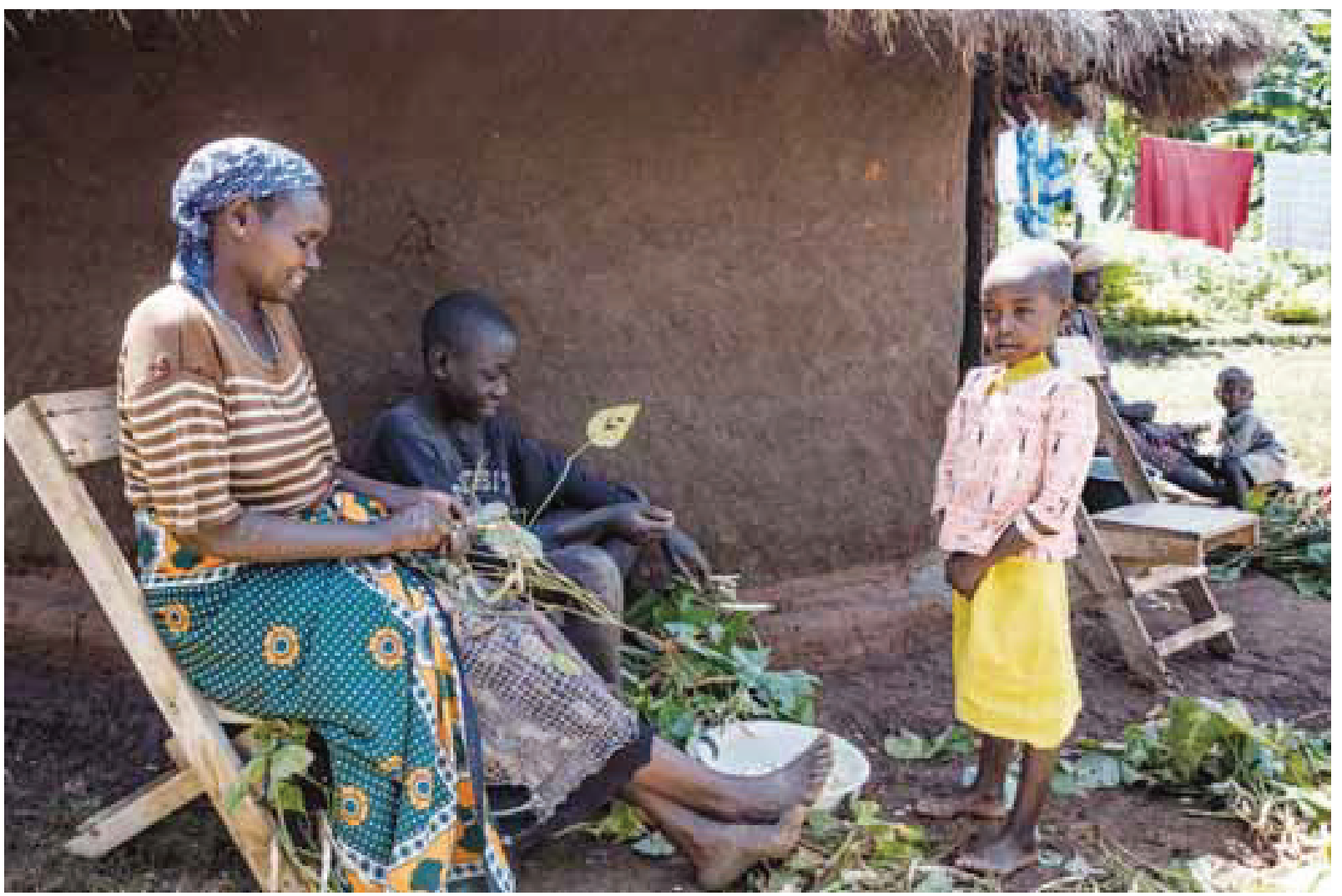

Irene (far left) and her children prepare dinner at her home in Tomboboi town, Eastern Uganda. She is a survivor of infibulation. 


\section{Women for peace}

The Virgins for Peace are a collective of women in Pibor, a small town in the east of South Sudan. They are part of the Murle tribe, who for generations have been struggling with both inter-tribal violence and external violence. Pibor is built with iron sheets and old refugee tarpaulin tents, as some years before, during the war, it had been completely burnt to the ground, and thus resources are very scarce. The Murle men are divided into generational groups, in a type of hierarchy, and they are all prone to gun violence between the groups and these incidents are often deadly.

'We are tired of losing our sons and our husbands', says Rebecca, one of the women leaders. These women vary in age, and most of them are mothers and grandmothers. They go out into the bush to talk to different groups of men, from youth to older ones, to stop them from fighting and, basically, to tell them off. Since they have been doing this, the level of violence has decreased and the men are beginning to understand the effects and consequences that the fighting can have on their families. Sometimes the women walk for days to visit a cattle camp, as this is a pastoralist culture and men go out into the bush for weeks or months to graze their cattle.

South Sudan descended into a war in 2013, mostly led by tribal disputes between the two main tribes in the country. Since then, more than 400,000 people have been killed and a million have been displaced to neighbouring countries such as Uganda, Kenya, Ethiopia, and the Democratic Republic of Congo. In 2019, a peace agreement between the two warring parties was signed; however, it remains fragile and tense.

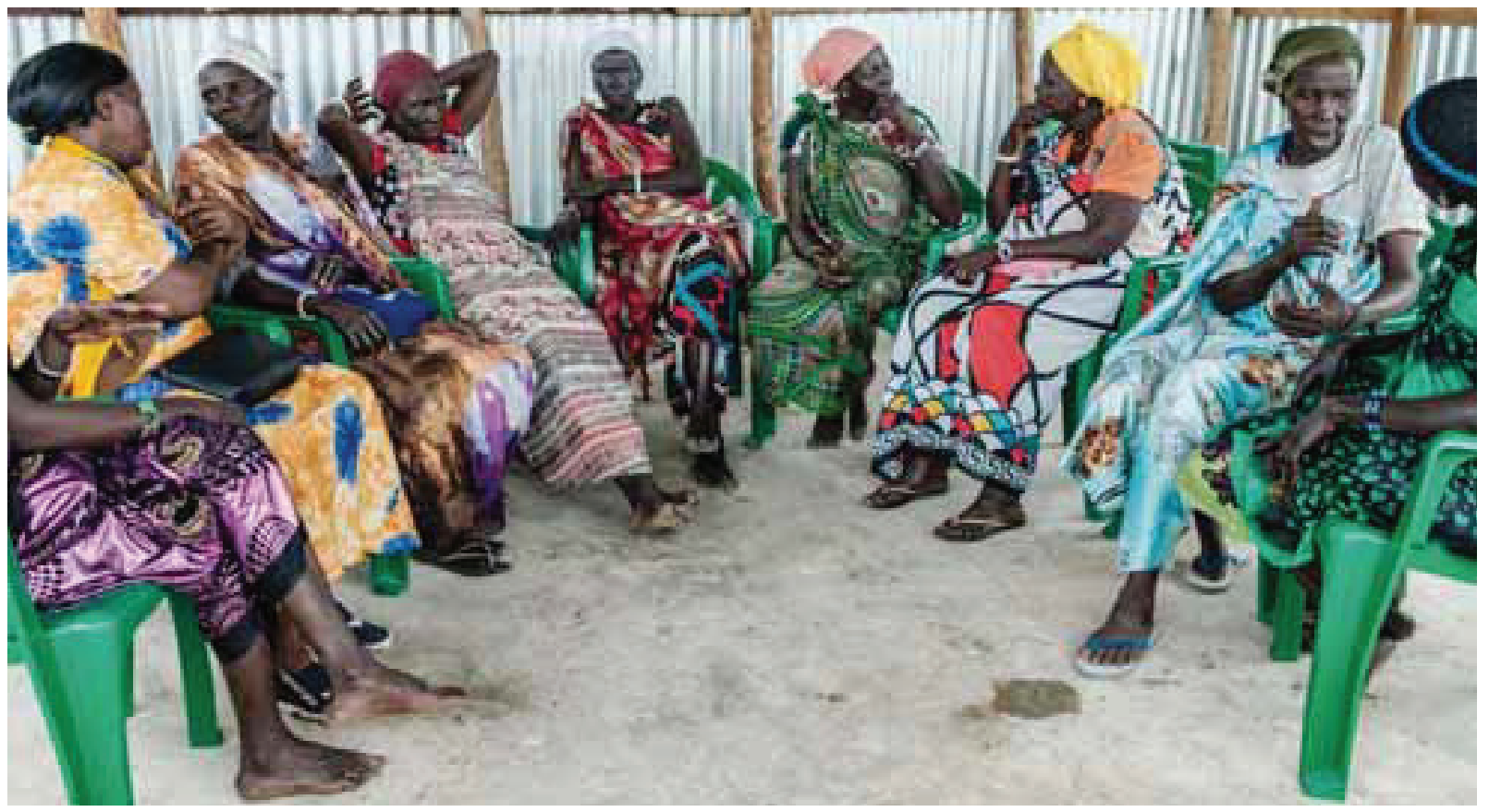

The Virgins for Peace in South Sudan meet up regularly to discuss how they will stop intertribal violence within their communities. 


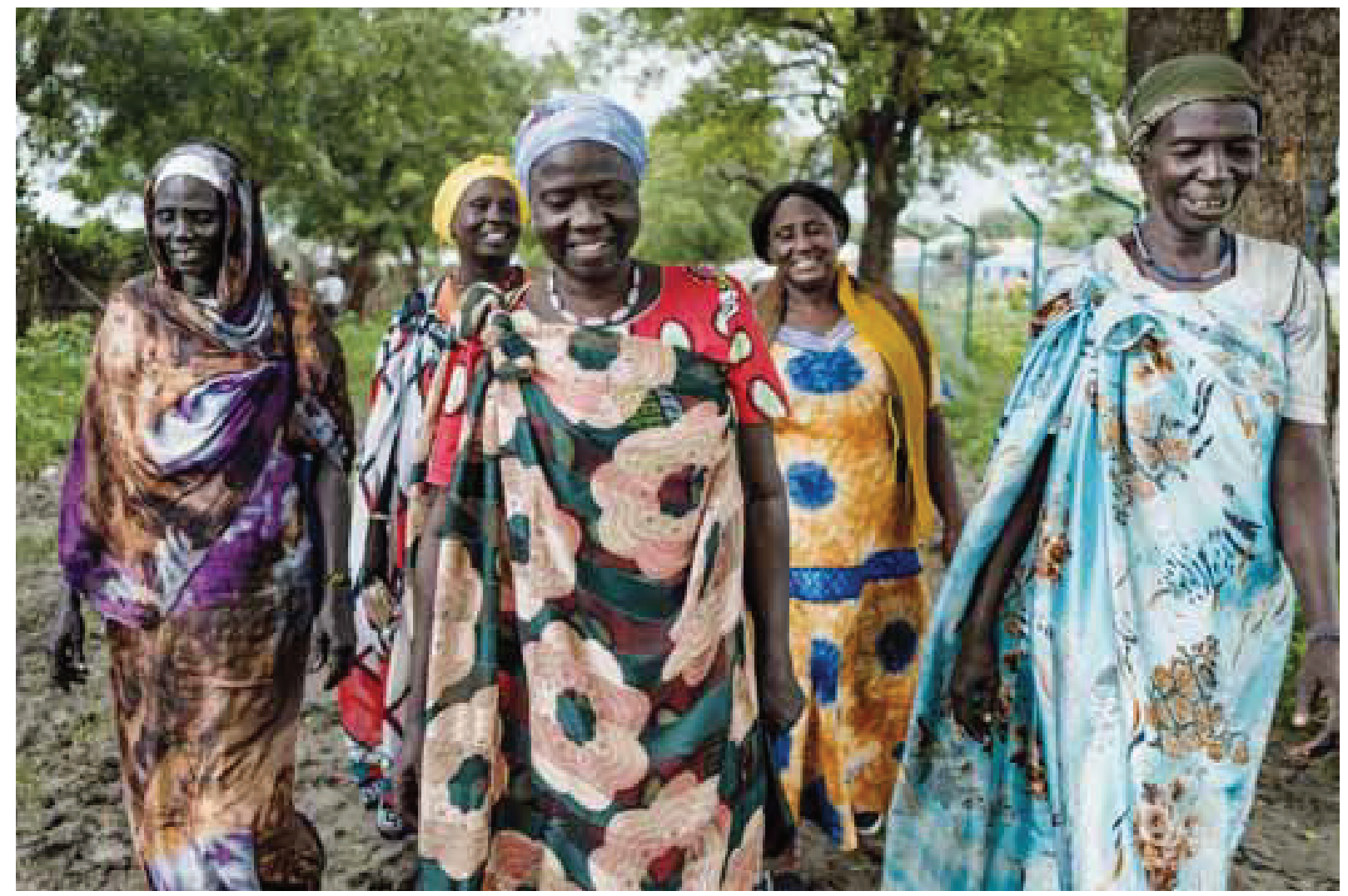

The Virgins for Peace in South Sudan are women from Pibor, in South Sudan, fighting for peace within their communities as well as inter-tribal communities.

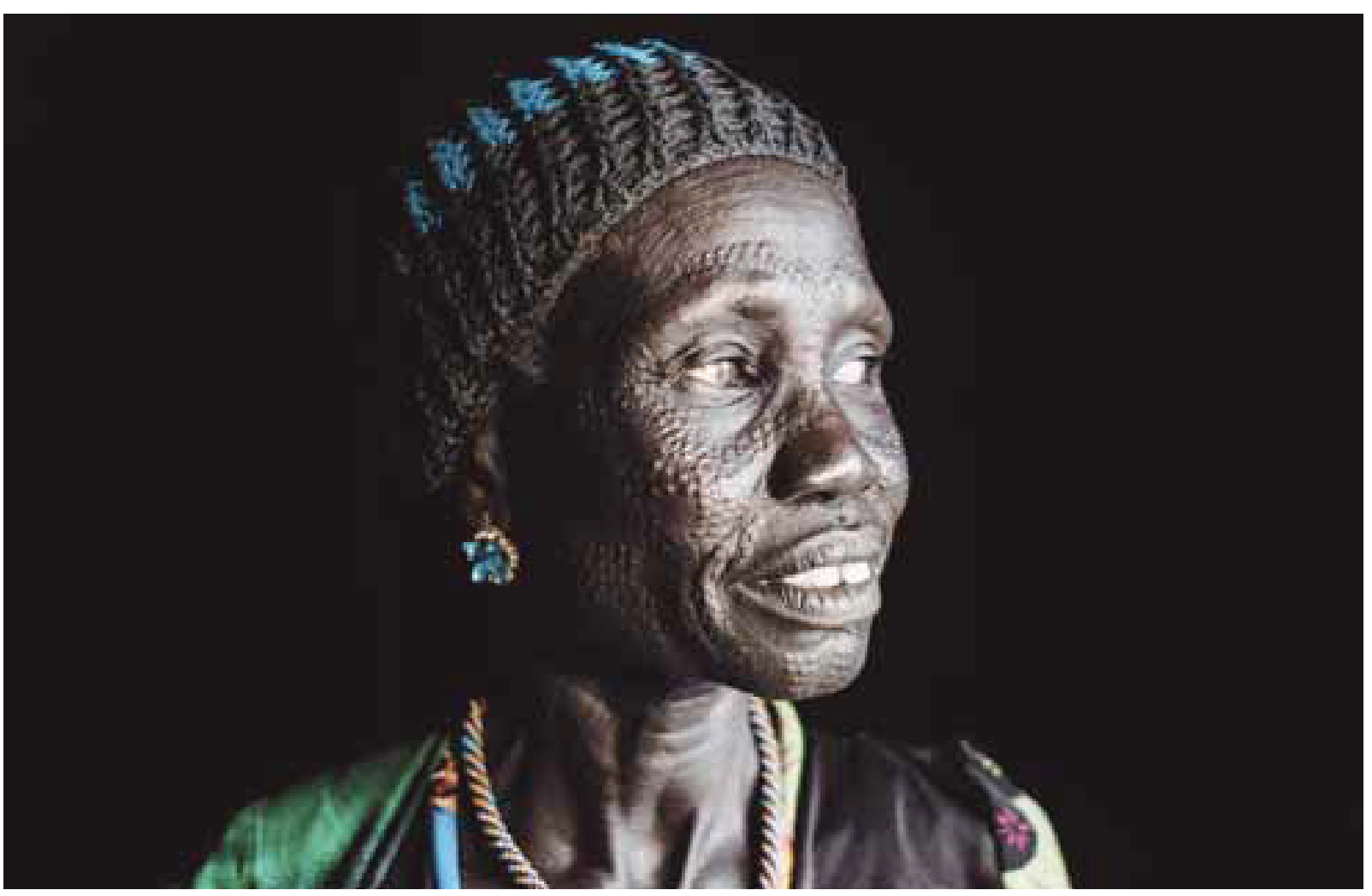

A member of the Virgins for Peace in South Sudan. 


\section{DOKUMENT / THE GENDER FILE}

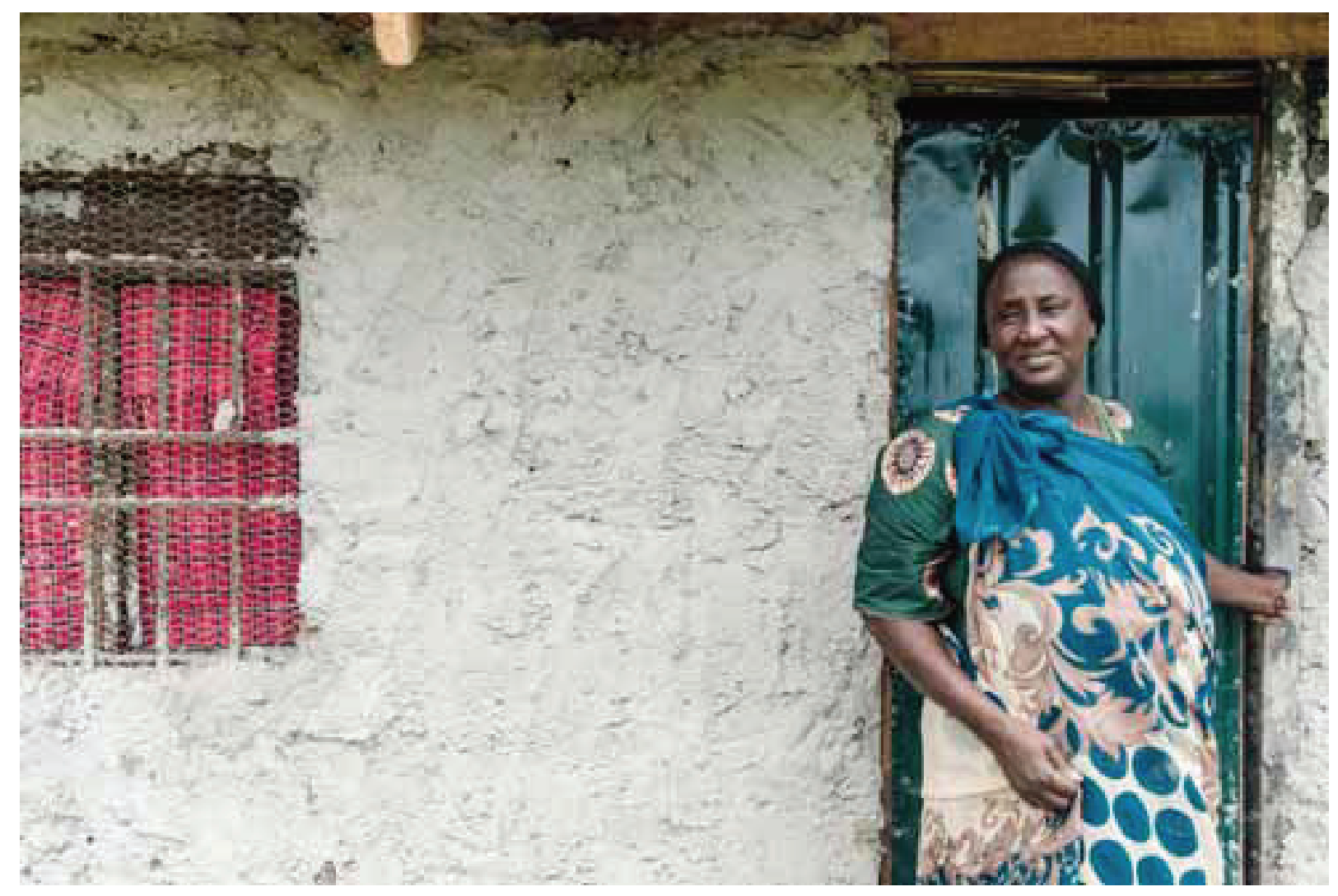

Rebecca, a leader of the Virgins for Peace in South Sudan, at home.

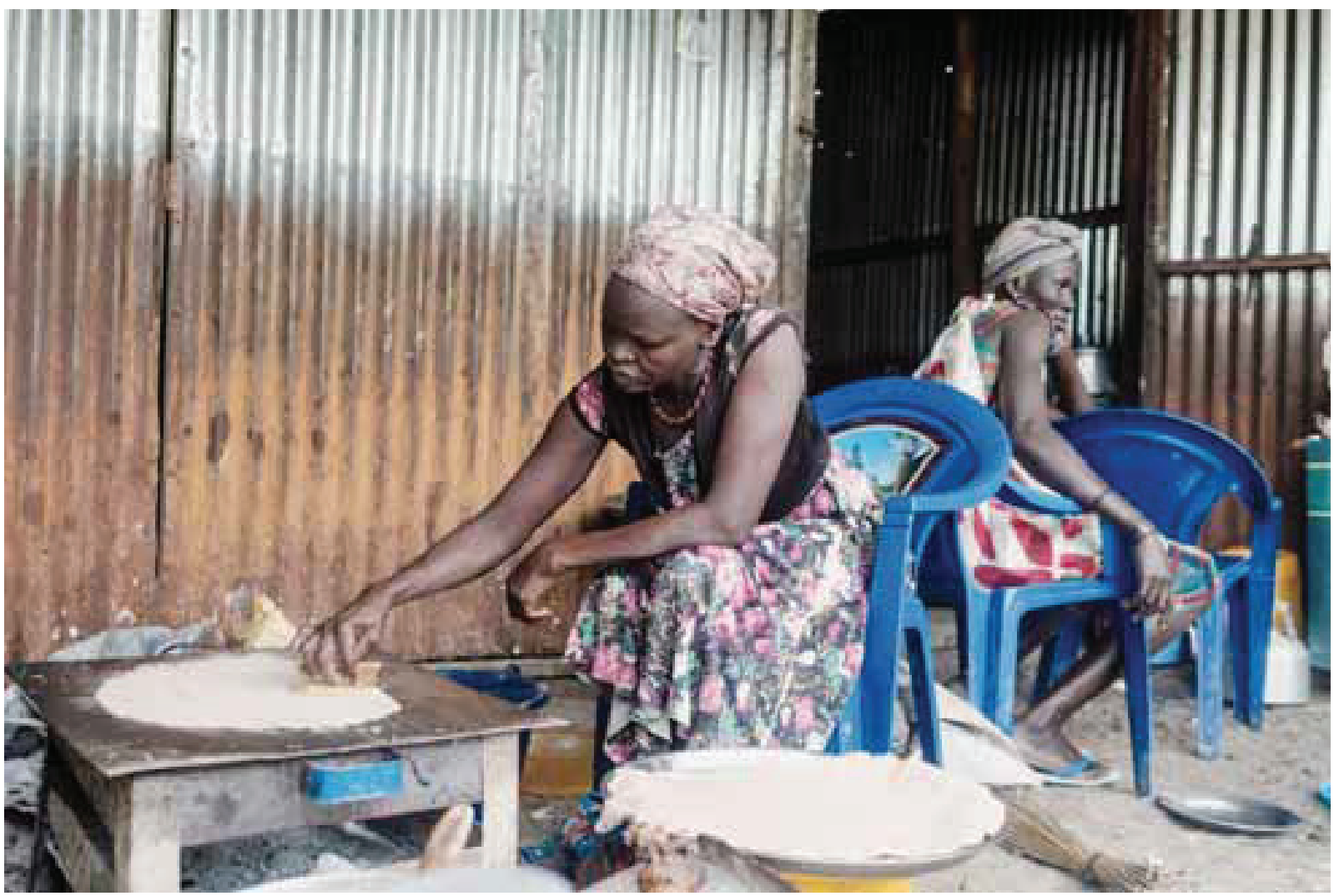

Women in Pibor town, South Sudan, prepare traditional food to sell in their small restaurant. 


\section{Uganda on lockdown}

Like many other countries around the world, Uganda has been on lockdown since 30 March in order to slow down the spread of COVID-19. It has had one of the most successful responses to the pandemic in the East Africa region, as it imposed the lockdown fairly quickly and completely closed the borders before any other nations did.

The landscape of the city of Kampala changed radically. The usually vibrant streets were deserted, and the energetic social life was diminished by social distancing rules. Schools were closed, public and private transport was prohibited to operate, except vehicles with special stickers for people who are considered essential workers: politicians, lawyers, medical personnel, bank staff, and journalists, for example. Food markets and shops were allowed to be open but had to maintain strict hygiene and social distancing rules. Water tanks were installed and hands had to be washed before entering anywhere, people had their body temperature checked.

Since a large majority of Ugandans live on a day-to-day income, many who were not able to work were economically affected by this lockdown. The Government of Uganda began a food distribution campaign at the beginning of April for households that were deeply impacted. However, distribution was slow, and many suburbs of Kampala were still waiting to receive their portions in May.

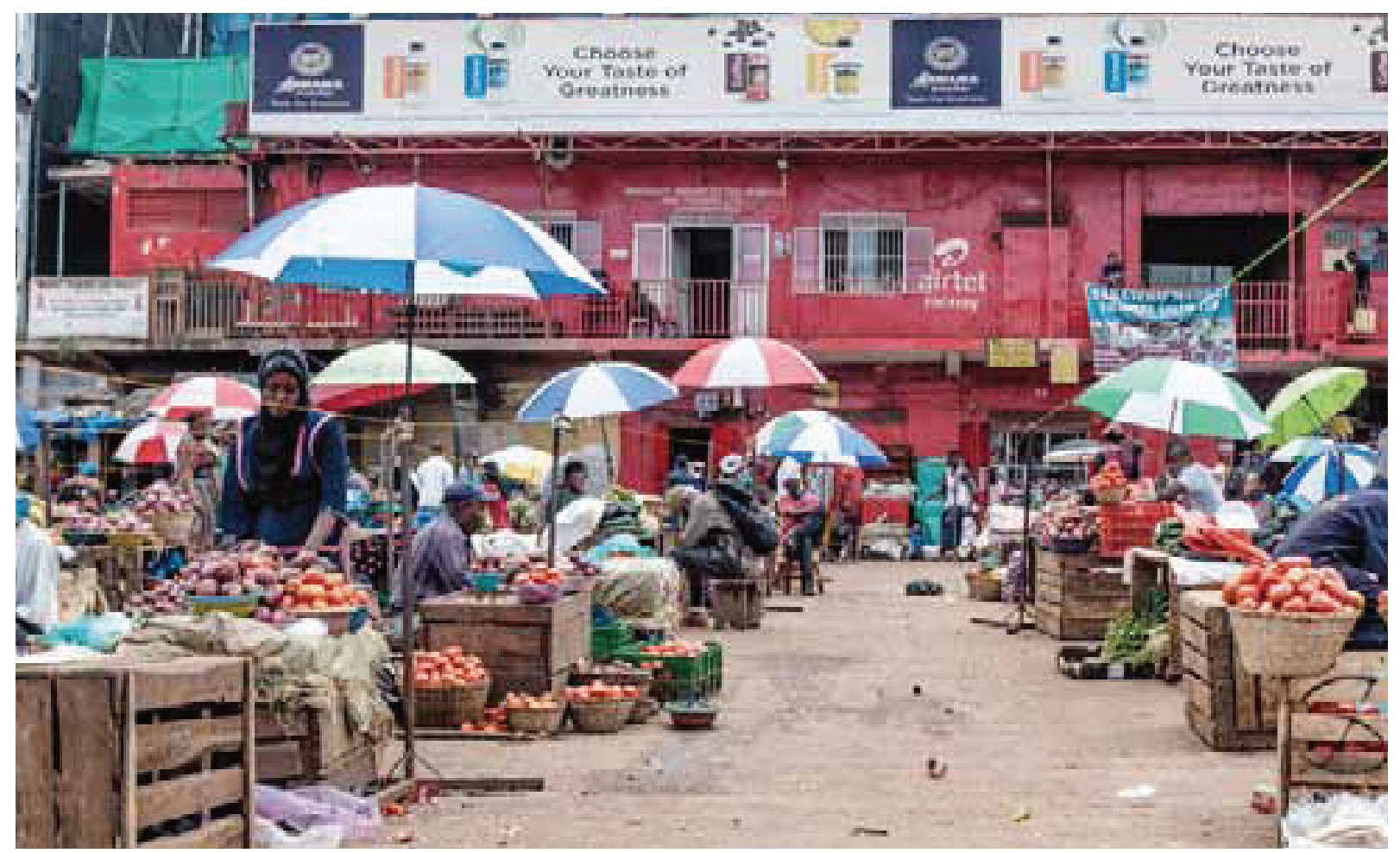

Nakasero market in Kampala attempts to maintain social distancing during the lockdown imposed to stop the spread of COVID-19. 


\section{DOKUMENT / THE GENDER FILE}

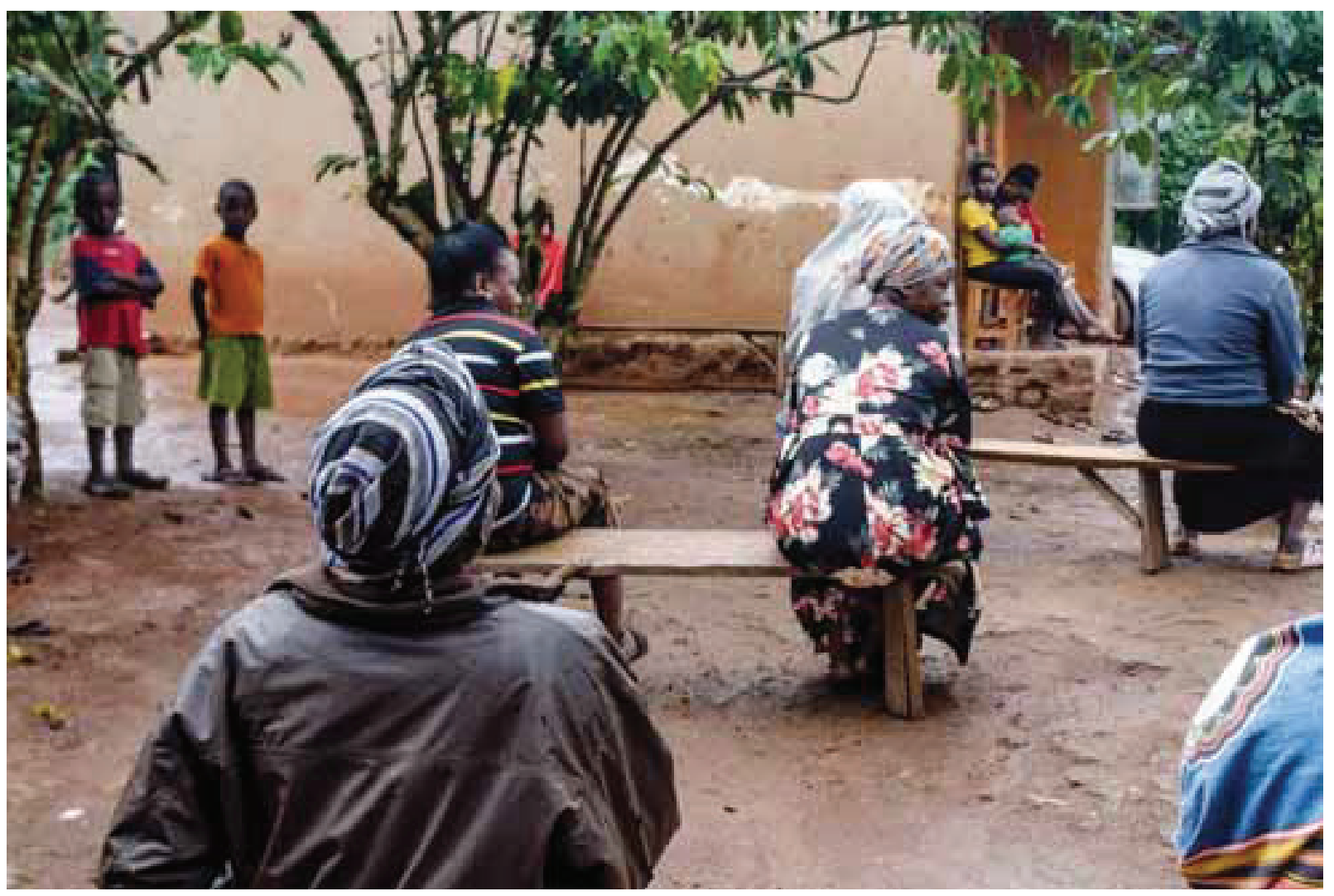

Basket weavers in Mpigi practising social distancing while waiting for the distribution of essential household items.

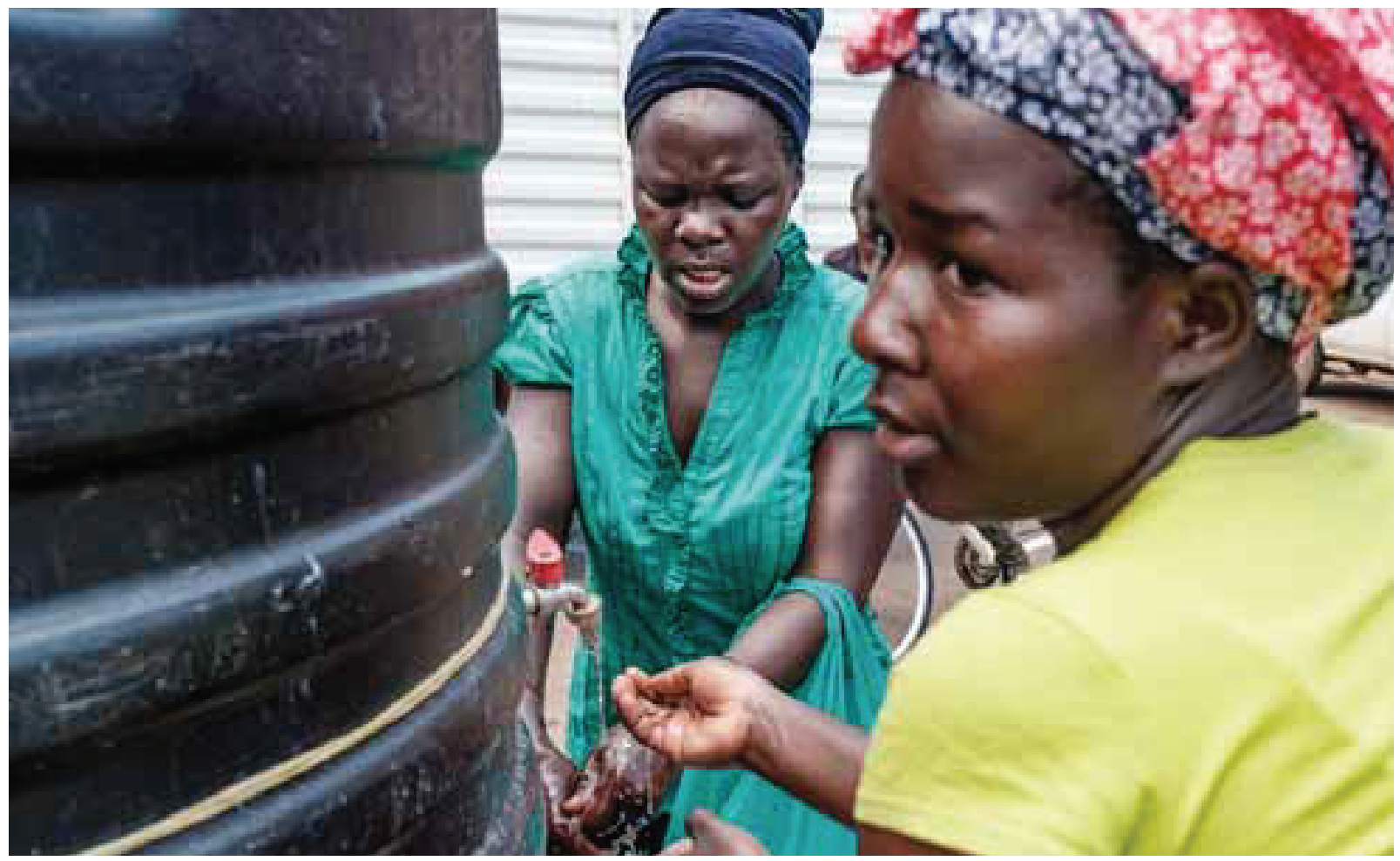

Women in Nakasero market wash their hands before entering, as a new rule imposed to stop the spread of COVID-19. 


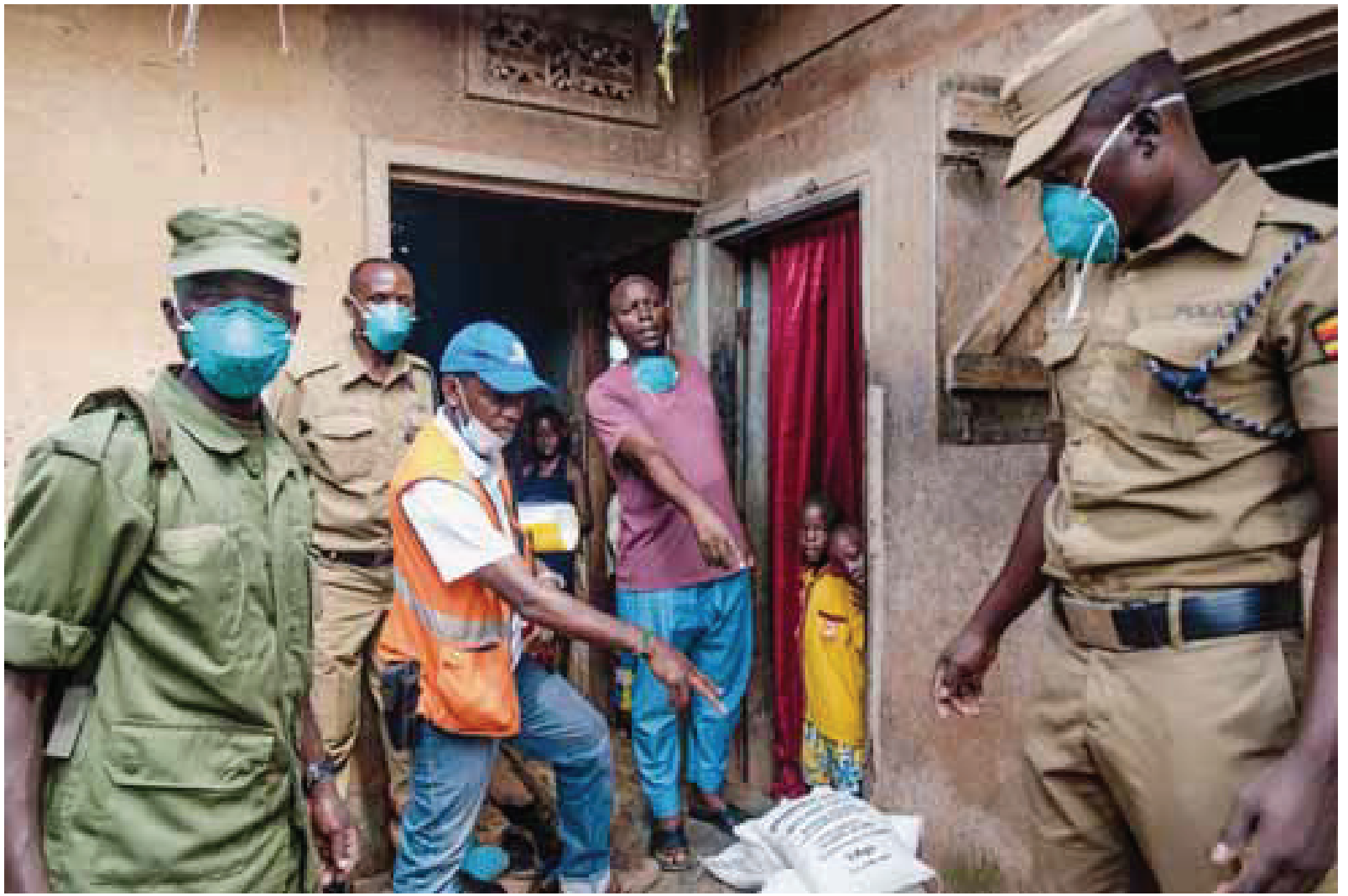

Food distribution takes place in Kampala for families that have been economically affected by the lockdown imposed to stop the spread of COVID-19.

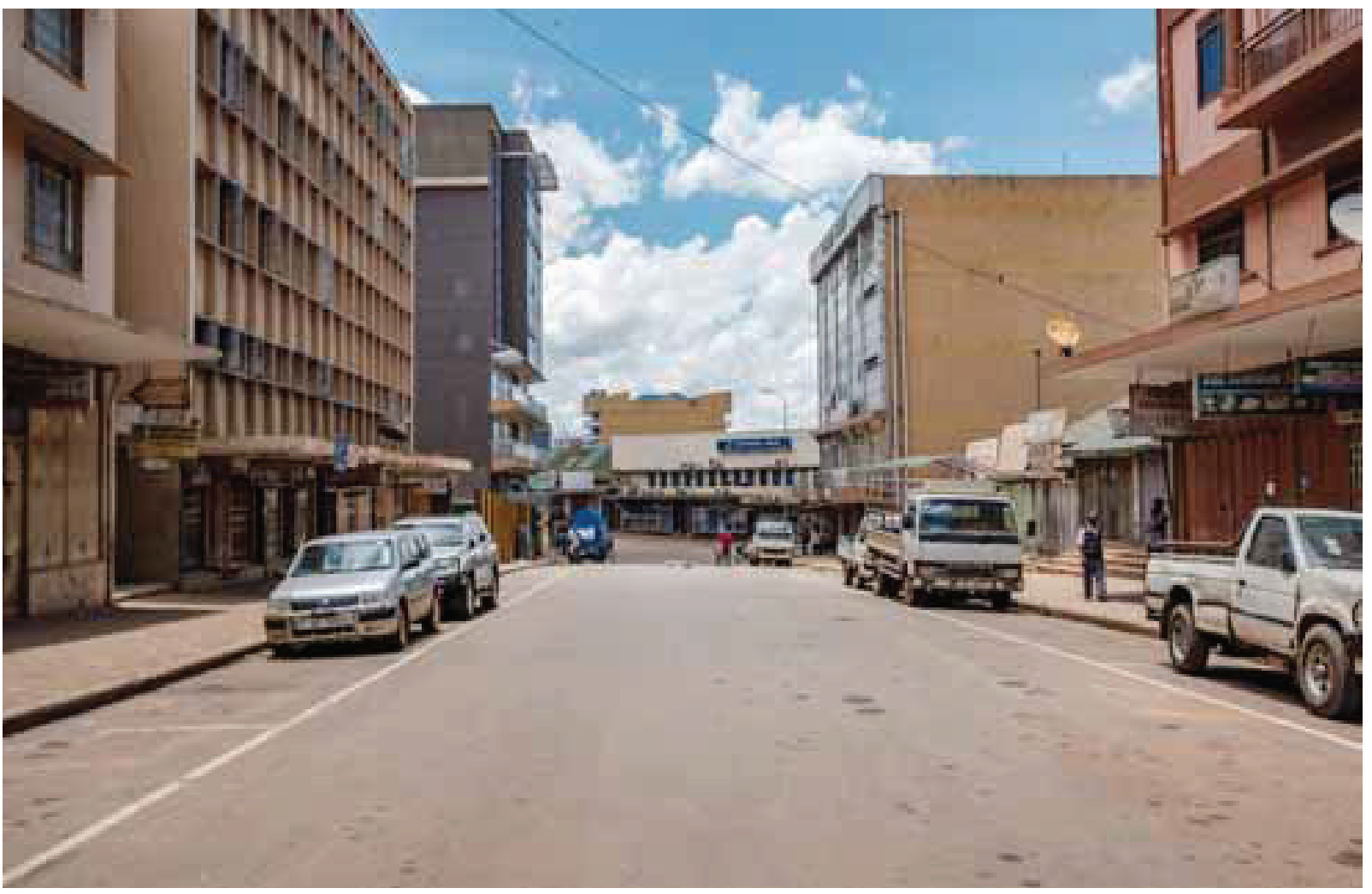

Kampala's streets are empty during the lockdown imposed to stop the spread of COVID-19. 


\section{DOKUMENT / THE GENDER FILE}

\section{Women's protest}

On 9 July 2018, female activists took to the streets of Kampala to demonstrate against the government's lack of response to a series of feminicides that took place that year. Around 30 women were brutally murdered in the space of around four months, and the cases were never solved and barely investigated by police. There were no suspects, though it seemed to be done by the same killer, as there were similarities to the way in which the women were murdered and displayed to the public. The women protested the lack of extra protection on the streets, particularly in areas such as Wakiso and Nansana, where many of these young women were killed. Since then, the investigations have been dropped and all the cases were forgotten.

The protesters demanded action, accountability, and protection: 'women's lives matter' was the main slogan. This was also the first protest of its kind, as usually Uganda has a no right to protest rule. Generally, marches are broken up by the police fairly quickly with tear gas and the arrival of riot police. This one was allowed to take place and there was no violence.

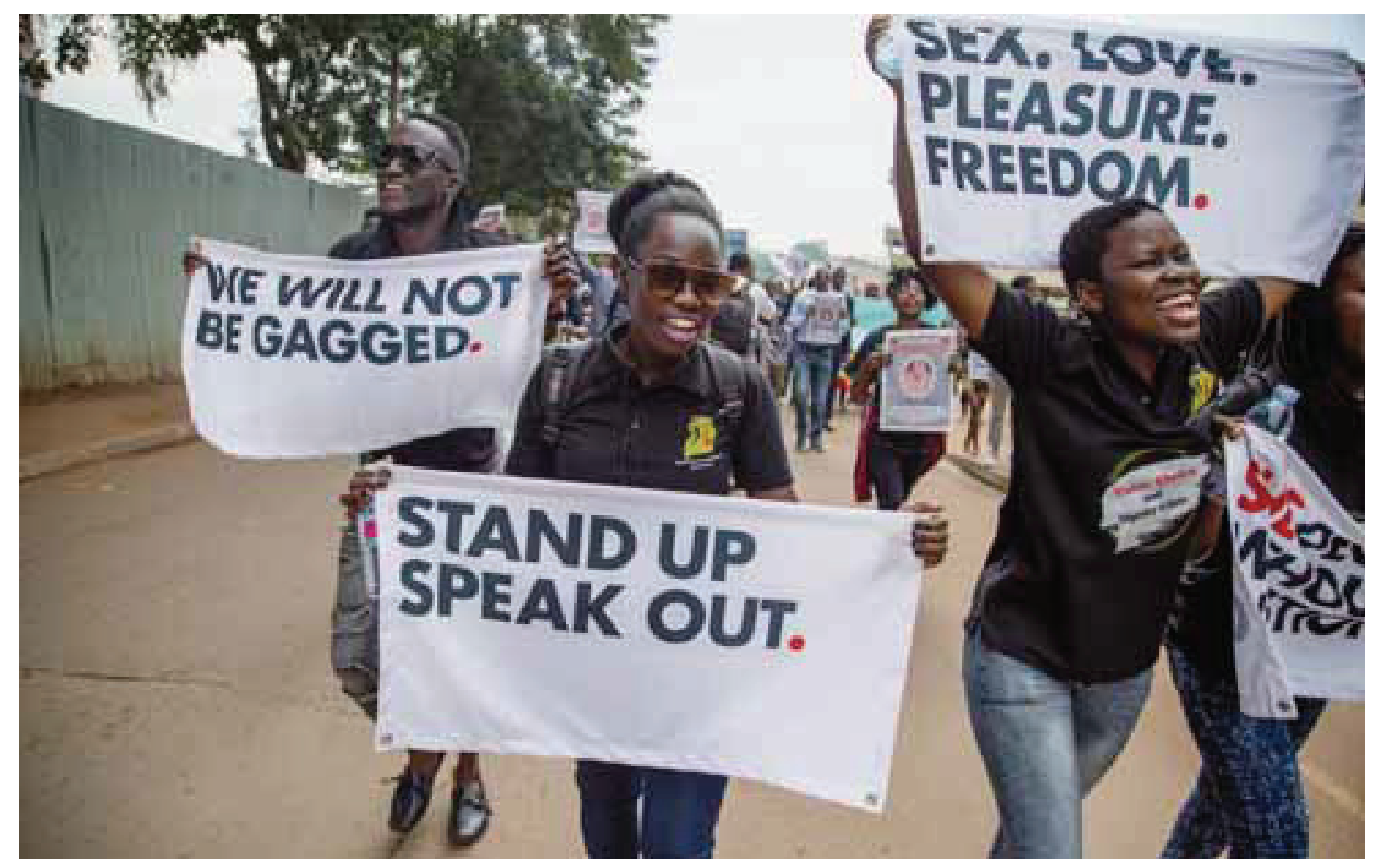

Women protest for women's rights in Kampala on 9 July 2018. 


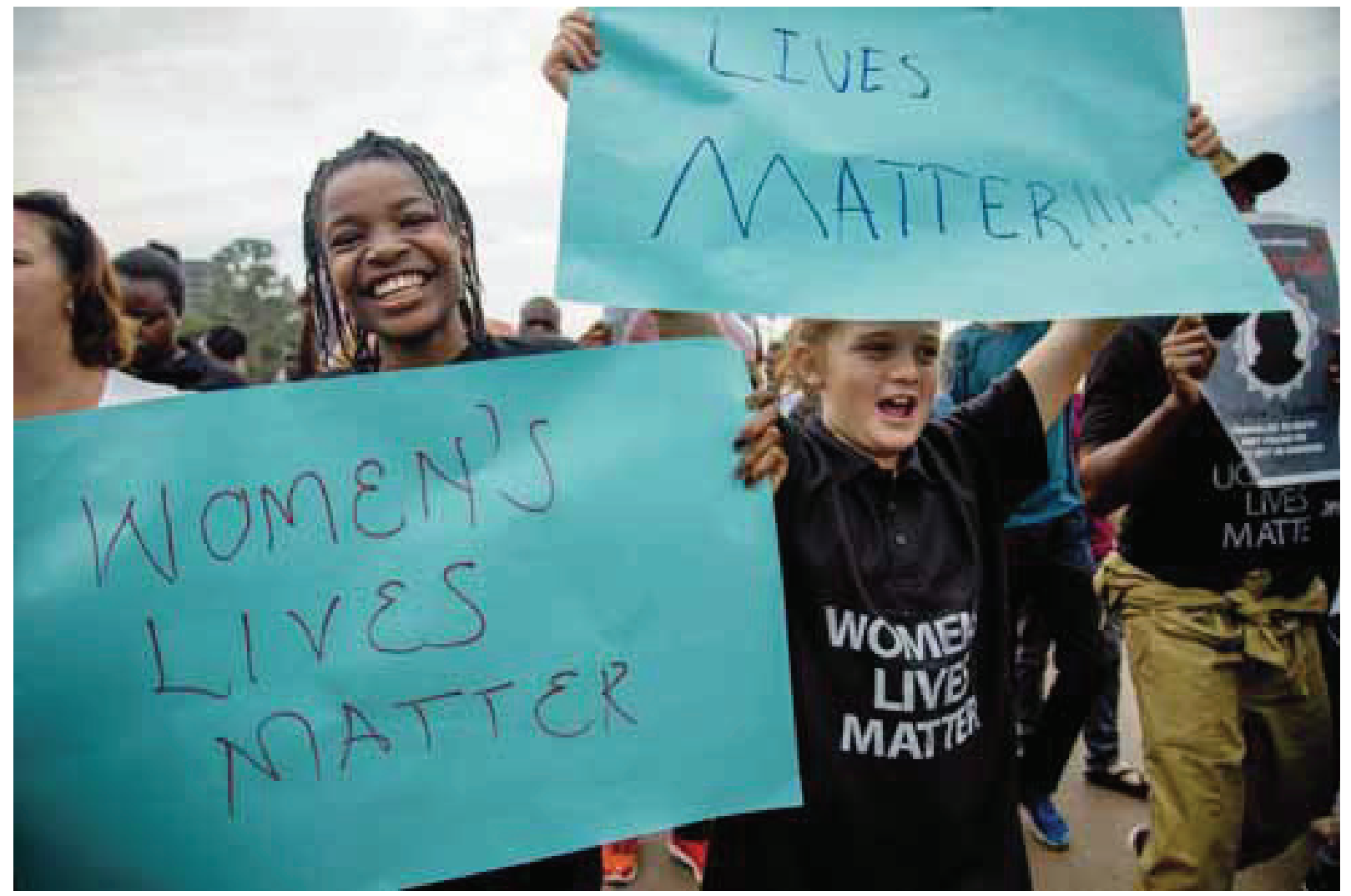

Children joining a march for women's rights in Kampala on 9 July 2018.

Sumy Sadurni is a photo-journalist in Kampala, Uganda. Her work focuses on human and gender rights, society, and politics. Website: www.sumysadurni.com. Contact email: sumysadurni@gmail.com.

(a) BY-NC Sumy Sadurni, 2020.

(a) BY-NC Institute of Sociology of the Czech Academy of Sciences, 2020. 